
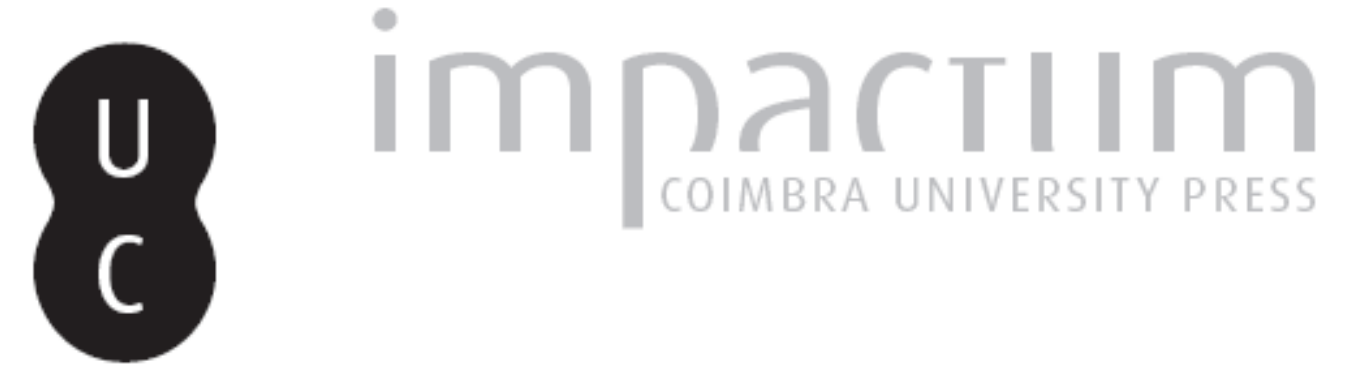

\title{
The analysis of the concept of vulnerability on the international legal framework on human trade
}

\author{
Autor(es): $\quad$ Pascoal, Rafaela Hilário
}

Publicado por: Imprensa da Universidade de Coimbra

URL

persistente:

URI:http://hdl.handle.net/10316.2/43064

DOI:

DOI:https://doi.org/10.14195/1647-6336_17_5

Accessed : $\quad$ 26-Apr-2023 10:29:40

A navegação consulta e descarregamento dos títulos inseridos nas Bibliotecas Digitais UC Digitalis, UC Pombalina e UC Impactum, pressupõem a aceitação plena e sem reservas dos Termos e Condições de Uso destas Bibliotecas Digitais, disponíveis em https://digitalis.uc.pt/pt-pt/termos.

Conforme exposto nos referidos Termos e Condições de Uso, o descarregamento de títulos de acesso restrito requer uma licença válida de autorização devendo o utilizador aceder ao(s) documento(s) a partir de um endereço de IP da instituição detentora da supramencionada licença.

Ao utilizador é apenas permitido o descarregamento para uso pessoal, pelo que o emprego do(s) título(s) descarregado(s) para outro fim, designadamente comercial, carece de autorização do respetivo autor ou editor da obra.

Na medida em que todas as obras da UC Digitalis se encontram protegidas pelo Código do Direito de Autor e Direitos Conexos e demais legislação aplicável, toda a cópia, parcial ou total, deste documento, nos casos em que é legalmente admitida, deverá conter ou fazer-se acompanhar por este aviso.

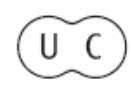




\section{DEBATER \\ A EUROPA}

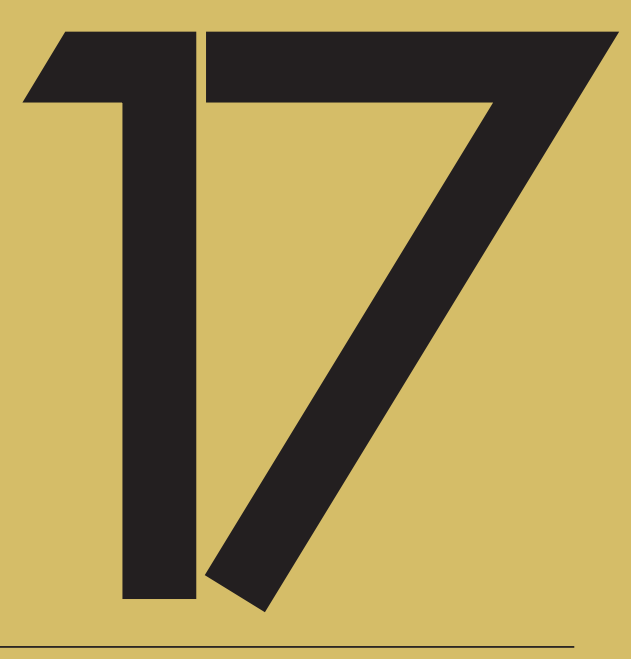

jul-dez 2017

UNIÃO EUROPEIA E O COMBATE AO
TRÁFICO DE SERES HUMANOS

THE EUROPEAN UNION AND COMBATING

TRAFFICKING IN HUMAN BEINGS 


\title{
The analysis of the concept of vulnerability on the International legal framework on Human Trade
}

\author{
Rafaela Hilário Pascoal, PhD student \\ Università di Palermo \\ E-mail: rafaelahilariopascoal@gmail.com
}

\begin{abstract}
The establishment of the Trafficking ${ }^{1}$ and the Smuggling Protocol ${ }^{2}$ has brought to the surface the importance of the concept of vulnerability. However, the Protocols have not given a precise definition to the concept of vulnerability, in order to perceive a practical application on legal grounds. In 2005, the Council of Europe tries to delimit the definition's gap of such concept, through the Convention of Warsaw ${ }^{3}$, giving a more exact definition of the concept. The present article intends to analyse the evolution and the application of this concept on the international legal framework on Human trafficking and Smuggling of migrants.
\end{abstract}

Keywords: Vulnerbaility; Human Trafficking; Human Smuggling; International Legal Framework; Protection.

\section{Evolution of the concept of Vulnerability on the International Legal Framework on Human Trafficking}

During the last Century the International Legal Framework on Trafficking has rapidly emerged, passing from a major focus on sexual exploitation of white women ${ }^{4}$ to a wider concept that includes other exploitative typologies, with a more inclusive concept of vulnerability. Hence, the International agreements and Protocols in Human Trafficking have passed from a perspective focused only in a particular vulnerable category, limited by

1 Protocol to Prevent, Suppress and Punish Trafficking in Persons, Especially Women and Children Adopted and opened for signature, ratification and accession by General Assembly resolution 55/25 of 15th November 2000, entered in force on 25th December 2003.

2 The Protocol Against The Smuggling of Migrants by Land, Sea and Air was adopted and opened for signature, ratification and accession by General Assembly resolution 55/25 of 15th November 2000entered into force on 28 January 2004.

3The Council of Europe Convention on Action against Trafficking in Human Beings was adopted by the Committee of Ministers of the Council of Europe on 3 May 2005, entered in force on 1st February 2008.

4 The International Agreement for the suppression of the White Slave Traffic, concluded in Paris on 18th May 1904 and came into force on 18 July 1905. The Treaty was ratified by 26 States and later renegotiated and concluded on 4th May 1910, coming into force on 5th July 1920 and being ratified by 41 states. 
the feminine gender, into an individual concept of vulnerability applied to every single individual that shares the so-considered vulnerable features.

Despite that the term "Abuse of authority" has previously appeared in the international conventions, such as the 1910's White Slavery Convention, the concept of Vulnerability has been only introduced at an International level through the European Parliament's Resolution A4-0326/95 on Trafficking in Human Beings in 1995. The document inserts the concept not only regarding to a potential vulnerable group, mainly sharing a gender or age, but also at a more individual level. Furthermore, the introduction of such concept is not only restricted to a potential vulnerable group as in previous International Legal Instruments on Human Trafficking, but also introduced as one of the "means", one of the three elements (Act, Means and Purpose) that constitute the phenomenon of trafficking. The concept, on this way is considered as a "mean", which the trafficker uses to obtain the victim's consent, by the "abuse of a person's vulnerable situation". Moreover, the Resolution also admits the urge to draw legislation, in order to reduce the victims' vulnerability and access to protection services. In fact, it is understandable that the Resolution not only understands the victim's vulnerability during the recruitment's act and exploitation, but also after the exploitation period, since it recommends to the European Union member States to avoid deportation, which probably exposes the victim to further exploitation.

Nevertheless, the concept of vulnerability was only taken at a wider International level by the United Nations, with the establishment of the Human Trafficking ${ }^{6}$ and the Migrant Smuggling Protocols, after the United Nations Convention Against Organized Crime, in 2000. The consideration of the individual vulnerability emerges during the Travaux Preparatoires of the Trafficking Protocol that, in spite of the fact that most member States admitted that the phenomenon was more prevalent on women and children, they showed preference to target all individuals, rather than only focusing on these two groups.

The concept of abuse of a position of vulnerability has been considered as an important part of the international legal definition of THB (UNODC, 2013), despite of its ambiguity and unlimited characteristic. Therefore, a precise definition of "APOV" was later given on other International Agreements in $\mathrm{THB}^{7}$ and the Protocol's Legislative Guide as "any situation in which the person involved has no real and acceptable alternative, but to submit to the abuse itself." Nevertheless, despite a clearer definition on "abuse of position of

5 Official Journal C $032,05 / 02 / 1996$ P. 0088

6 Art 3, "Trafficking in persons" shall mean the recruitment, transportation, transfer, harbouring or receipt of persons, by means of the threat or use of force or other forms of coercion, of abduction, of fraud, of deception, of the abuse of power or of a position of vulnerability or of the giving or receiving of payments or benefits to achieve the consent of a person having control over another person, for the purpose of exploitation. Exploitation shall include, at a minimum, the exploitation of the prostitution of others or other forms of sexual exploitation, forced labour or services, slavery or practices similar to slavery, servitude or the removal of organs".

7 Referring to the European Convention on Human Trafficking 2005 and the European Directive 2011/36/EU 
vulnerability", the provided definition was still regarded as unclear, due to the imprecise meaning of "real and acceptable alternative".

The concept of Vulnerability, after its first introduction in the Legal Framework at International level, has been often referred in other Legal instruments regarding to the phenomenon of Human Trafficking. The Brussels Declaration on Preventing and Combating Trafficking in Human Beings (2002) has introduced the concept of vulnerability mainly referring to vulnerable groups, by identifying women as object of gender discrimination and applying a gender approach. Such concept is mainly used as a preventive measure, as it will be considered in other International Legal Instruments addressing the phenomenon of Human Trafficking. In 2004, the Council Directive 2004/81/EC ${ }^{8}$ identifies thirdcountry nationals human trafficking victims as being particularly vulnerable that should be granted with protection by the member states. Furthermore, the Directive highlights the necessity to provide special protection to the most vulnerable victims, in order to fulfill their special needs. Further precision was given to the concept of vulnerability by the Warsaw Convention (2005) $)^{9}$, which also urges the Member States on the protection of vulnerable individuals and their special needs as well as the adoption of a gender mainstream to tackle human trafficking.

The gender approach indicates the concern of European Union by the gender inequality, reflecting the vulnerability of women, by lacking of participation and empowerment in all public and private spheres. Furthermore, the Explanatory Report of the Warsaw Convention identifies the particular vulnerability of women, especially exposed of a major risk for degrading and inhuman treatment than men and urges the States to promote measures that empower women and equality between sexes. It is obvious that most trafficking victims tend to share common features that can lead them to traffickers, yet the exposition to trafficking should not only be reviewed as a passive vulnerability, depending on the victim's background, but also a created vulnerability in exposure with a criminal network or trafficker (UNODC, 2012).The Warsaw Convention has also inserted as "means" the concept of "abuse of power or a position of vulnerability, which is defined as "abuse of any situation in which the person involved has no real and acceptable alternative to submitting the abuse". Moreover, the Convention also goes beyond the definition mentioned on the Protocol, by considering that "vulnerability maybe of any kind, whether physical, psychological, emotional, family-related, social or economic"10. Therefore, the

8 29th April 2004, Council Directive 2004/81/EC, on the residence permit issued to third country nationals who are victims of trafficking in human beings or who have been the subject of an action to facilitate illegal immigration, who cooperate with the competent authorities.

9 The Council of Europe Convention on Action against Trafficking in Human Beings was adopted by the Committee of Ministers of the Council of Europe on 3 May 2005, following a series of other initiatives by the Council of Europe in the field of combating trafficking in human beings. The Convention entered into force on 1 February 2008.

10 "The vulnerability may be of any kind, whether physical, psychological, emotional, family-related, social or economic. The situation might, for example, involve insecurity or illegality of the victim's immigration 
provided definition by the Warsaw Convention on the concept of vulnerability, includes different approaches of vulnerability that can be attributed not only as a passive dimension based on the victim's features and conditions, but also an active vulnerability that can be created by the exploiter. For instance, emotional vulnerability can be regarded on the loverboy method ${ }^{11}$, in which the trafficker intentionally and actively creates the emotional vulnerability of the victim, in order to achieve consent or maintain the exploitation.

The Explanatory Report of the 2005 Convention summarises the vulnerability's definition as "the situation can be any state of hardship in which a human being is impelled to accept being exploited. Persons abusing such a situation flagrantly infringe human rights and violate human dignity and integrity, which no one can validly renounce". While another definition of vulnerability is proposed by Michèle Clark at the UNODC Background Paper for the Vienna Forum 2008, regarding the concept as "a condition resulting from how individuals negatively experience the complex interaction of social, cultural, economic, political and environmental factors that create the context for their communities" (Clark, 2008)

The UNODC Model Law in Trafficking in Persons (2009) differs in two definitions as the "abuse of position of vulnerability" and "taking advantage of position of vulnerability", where the Model Law in Trafficking suggests a list with several possibilities and finishes with an open end list, which assumes the infinitive possibilities regarding one's vulnerability. For instance, due to the extensive possibilities of potential vulnerable situations, the Model Law on Human Trafficking (UNODC, 2009) suggests that governments should concentrate on the profile of the offender, rather than the vulnerable situation itself of the victim. Furthermore human trafficking victims tend to come from backgrounds that include situations of conflict, disaster or violation of human rights, which increases groups' or individuals' vulnerability to traffickers. For instance, during conflict situations, individuals can be abducted in order to provide labour, military and sexual services. (Wolte, 2004). Moreover, also post conflict situations diminish inhabitants into vulnerable situations, since the population might still be exposed to economic pressure and exposed to violent movements or rebels. Conflict situation also tends to obligate individuals to displace from their homes and expose them to organized criminal networks.

Other International reports and studies (ILO, 2009) have tried to define vulnerability, especially on the use of indicators to identify the victims, based on "precarious financial, psychological, and social situation, as well as on linguistic, physical, and social isolation". However, these indicators have been mainly applied on the course of investigators and not

status, economic dependence or fragile health. In short, the situation can be any state of hardship in which a human being is impelled to accept being exploited. Persons abusing such a situation flagrantly infringe human rights and violate human dignity and integrity, which no one can validly renounce."

11 The loverboy method has been identified by the Dutch government as a recruitment method, mainly used by the Eastern traffickers, in which the recruiter attracts the girl into human trafficking by grooming her. 
as identification indicators. Moreover, the conditions mentioned on the ILO's list are the same that can aggravate the offence of the perpetrator. ${ }^{12}$

The definition of abuse of position of Vulnerability, provided by the previous Convention of Warsaw and the UN Legislative Guide on Human Trafficking has been further taken and confirmed by the Directive 2011/36/EU, in its Art. 2.2. The Directive 2011/36/ EU has also emphasized the importance of reducing the vulnerability of individuals, by addressing trafficking root problems, especially in third countries by incentivizing appropriate anti-trafficking measures. The EU Strategy 2012-2016 also identifies gender inequality as well as violence against women as a vulnerability factor. Furthermore, the strategy also indicates other environment and contextual factors based on economy such as poverty, on political and social factors such as conflict and post-conflict situations, lack of social integration, lack of opportunities and employment and educational factors.

Despite that the recognition of gender inequality and violence can be considered a particular vulnerable factor to Human Trafficking, the EU Strategy also identifies that traffickers tend to target boys, men, girls and women in a vulnerable position. Moreover, the EU strategies identifies that vulnerability is shaped by gender, which influences both genders in being vulnerable to different types of exploitation. For instance, due to the work segmentation in many countries women and girls were identified to be more vulnerable to sex exploitation and domestic servitude, while men and boys tend to be more vulnerable to labour exploitation in certain sectors. Furthermore, trafficking related to conflict has also very strong gender influences, since men and boys are often use to supply military forces, while women tend to be exposed to force marriage, providing food to fighting forces and being sexual slaves (Rehn\& Sirleaf, 2002).

\section{Vulnerability as a prevention measure, category group and a consequence to exploitation}

In human trafficking operations, the vulnerability of the victim, especially based on common characteristics shared by ethnicities groups has mainly been used as an indicator of potential victims of human trafficking. The recognition of such vulnerable indicators has helped NGOs and law enforcement stakeholders in recognizing potential human trafficking victims. However, vulnerability indicators not only should be used on the victims' identification, but also to urge the states in addressing root causes of trafficking by the development of prevention policies and practices (UNODC 2008). In fact, according to Weber and Penedo (2015) the identification of vulnerability indicators can be also useful

12 [(i) Having entered the country illegally or without proper documentation;] Or [(ii) Pregnancy or any physical or mental disease or disability of the person, including addiction to the use of any substance; or [(iii) Reduced capacity to form judgements by virtue of being a child, illness, infirmity or a physical or mental disability; ] or [(iv) Promises or giving sums of money or other advantages to those having authority over a person; ] or [(v) Being in a precarious situation from the standpoint of social survival;] or [(vi) Other relevant factors.] 
for data collection, in order to provide substantial analysis on Human Trafficking. Moreover, the researchers highlight that the indicators should be based in different grounds, including "gender; poverty; social and cultural exclusion; limited education; political instability, war and conflict; social, cultural and legal frameworks; movement under duress and demand."

According to Gallagher (2010) trafficking victims can be members of a particular social group that attract traffickers into introducing in human trafficking. The designation of particular vulnerable groups to trafficking, based on a geographic area has been recently indicated by High Courts and International Organizations in different countries. For instance in 2013, IOM has declared that the $80 \%$ of the Nigerian women coming through the Mediterranean were destined to sexual exploitation in Europe. Furthermore, in France, 3rd March 2015, following the request of the General Director of the Office Français de protection des réfugiés et apatrides to give a special status to Nigerian women, as being part of a social group exposed to criminal trafficking networks for sexual exploitation purposes, the French National Court of Asylum Right has declared that Nigerian women coming from Edo State were particularly vulnerable to sexual exploitation.

Therefore, according to the Paragraph A, 1st Article of the Geneva Convention 1951, Nigerian women were considered belonging to a particular vulnerable group sharing a common story, which, due to the reprobation of society as well the criminal networks based, especially on Edo state, the French state has recognized their exposure to risks and sexual exploitation. In fact, on the Ouagadougou Action Plan (2006) certain geographic areas are recognized to be particularly vulnerable to human traffickers. Also United Kingdom has recognized asylum for two Albanian trafficked victims, due their membership of a specific group highly exposed to traffickers. The indicators were based in different and broader factors, which included social and economic status, education level, mental health stability, area of origin, presence of an illegitimate child and age.

According to Gallagher (2010), individuals' and social groups' vulnerability can be influenced by environmental and contextual factors, leading to trafficking situations. Factors as poverty, inequality, discrimination and gender-based violence contribute to a higher marginalization of certain groups that tend to be misrepresented in society. Furthermore, the absence of visibility regarding to certain categories, such as prostitutes and domestic workers also increases their own vulnerability. Children are also considered a highly vulnerable group, being mainly considered by the European Commission's strategy against trafficking groups as early school leavers, unaccompanied minors, children left behind and with disabilities.

On the Issue paper on "Abuse of position of Vulnerability" (UNODC, 2012) the concept of vulnerability was analyzed within the National framework of different countries, such as Egypt, Republic of Moldova, Netherlands, Nigeria, United States of America, Belgium, Canada, Brazil, India, Mexico, United Kingdom and Switzerland. As a result of the inquiries on these countries, which were separated according to their inclusion on the concept of vulnerability on their national legal framework on Human Trafficking, 
the main features that can influence the victims' vulnerability are "age (youth and, less commonly, old age); irregular legal / migration status; poverty; precarious social status; pregnancy; illness and disability (mental and physical); gender (typically being female, but also transgender); sexuality, religious and cultural beliefs; isolation caused through inability to speak the language, lack of social networks; dependency (on employer, family member, etc); threats to disclose information to family members or others; and abuse of emotional / romantic relationships." (UNODC, 2012).

The mentioned vulnerability features were considered to be different on the origin country, mainly before and during the recruitment, and also in the destination country during and after the exploitation. For instance, the UK has identified factors such as age, illness, gender and poverty that tend to pre-exist the exploitation, being part of the push factors of the victims into the trafficker. Nevertheless, other features such as isolation, dependency and irregular status can be created vulnerabilities of the trafficker during the exploitation period, which can increase the victim's vulnerability to the trafficking situation. In some cases, for example connected to the loverboy method, the trafficker is the one that creates a situation of vulnerability in order to attract the victim to human trafficking. Hence, the trafficker creates an environment of dependency of the victim abusing from an emotional attachment in order to potentially target the victim. The creation of such pull factors introduces the concept of vulnerability not only to be thought from a passive situation of the victim, mainly based on her life experience and background, but also as an active situation, which is purposely created by the trafficker in order to target the victim. Therefore, in this case the UK has not only taken into account the loverboy method as a created vulnerability of the trafficker, but also the inclusion of oaths, which is typical from the Nigerian human trafficking for sexual exploitation purposes. The oath in these cases is not only used as a coercive instrument, but is also used by the trafficker as an advantage of the victim's spiritual believe, convincing the victim about the power of juju ritual. Furthermore, the traffickers also tend to use the presence of religious elements, such as religious statues or crosses during the ritual, which increases the believing of the victim on the ritual by also associating the ritual to their religious believes.

The use of psychological manipulation through the abuse and creation of emotional vulnerability as well as religious believes has been seen as being more effective on the victim's control. In fact this kind of coercion as well as vulnerability has been difficult to demonstrate on court during the procedures in several countries. Nevertheless, Romania has applied a measure in order to prove in court the emotional vulnerability of the victim by a psychological exam. The exam has not only been demonstrated to be successful in victims, but also in victims accused of trafficking who through the loverboy method have also started to recruit other women into sexual exploitation.

Despite that victims of trafficking tend to share a common feature, usually regarding to their gender, age, social or economic status, level of education or family background, 
Europol (2009) has identified that due to adverse personal circumstances, several victims do not fit into a victim's stereotype. On the contrary, individuals with high education levels, self-confidence or acknowledge of other languages can also be vulnerable due to a major mobility and travelling, access to low cost international transports and working opportunities abroad. On this case, the researchers Weber and Penedo identify three main categories of vulnerability that not only depend of the victim's background, but also on passive and active influence of other factors. Therefore, the authors divide vulnerability as being 1) preexisting, basically depending on the victim's background, such as a person's physical or mental disability, youth or old age, gender, pregnancy, culture, language, belief, family situation; 2) situational that can be created or maintained, such as legal status in one given territory or social, cultural or linguistic isolation; or 3) circumstantial (also created or maintained: such as a person's unemployment or economic destitution.

The difficulty on attributing an exact definition to the concept of vulnerability has been the source of several debates, which is confirmed on the Travaux Préparatoires. In fact, the concept was introduced after other suggestions of means, such as the "abuse of power"13, mentioned on previous International Conventions. Moreover, during the Travaux Préparatoires the concept "abuse of authority" came into debate, being mainly understood as "the power that male family members might have over female family members" (Gallagher, 2010).

Despite that major focus is given to the concept of vulnerability as one of the "Means" mentioned on Art 3 of the Trafficking Protocol and other International Legal Instruments on Human Traffickings, vulnerability has also been mentioned on both Protocols in prevention measures, as well as a consequence of trafficking. Thus, vulnerability is not considered a stable feature, but rather chronologically changeable. For instance, the Protocol, the Directive 2011 as well as the Warsaw Convention advise the States to give more attention to former victims, since they tend to be more vulnerable to revictimisation and find themselves in a "position of great insecurity"14. In addition, the EU Strategy urges a particular attention to the revictimisation of children, since according to an IOM Study (2010), $84 \%$ of revictimisation cases in a sample of 79 victims, were minors or recently adults.

Exploitation has a high psychological and emotional impact on the victims, which also tends to be increased by the fear of retaliation from the traffickers, especially after their denouncing. Regarding to the confront between the victim and the perpetrator in Court, the 2002 Brussels Declaration incentives the Member states to provide to the witnesses the use of audio-visual records in Court procedures, in order to avoid the offenders' intimidation on the victims. Regarding to the former victims, the International legal Instruments on Human Trafficking endorse the member states to avoid deportation of human trafficking victims in their origin countries, due to a higher vulnerability and

13 Nowadays, some countries have adopted the concept of abuse of power, rather than abuse of vulnerability. 14 Article 12 of the Warsaw Convention- Assistance for victims of trafficking 
exposure to the criminal organizations. As it was previously mentioned, former victims can also form a specific vulnerable group, since they share a specific element, based in their story usually involving persecution, reprisals or punishment. For example, in the case of Rantsev v. Cyprus and Russia ${ }^{15}$, the Human Rights European Court has accused Cyprus for not identifying the individual as a human trafficking victims and deport her to her origin country, exposing the victim to her traffickers.

Due to the isolation and high vulnerability of former victims, the Warsaw Convention identifies that language assistance should be given to the victims, since often the lack of knowledge of the destination country's language leads to a major isolation of the victim. Therefore, the International Legal instruments not only recognize the importance of vulnerability as one of the means for the identification of the victim, but also as a pull factor that should be addressed as a preventive measure. The recognition of vulnerable features in origin countries' population can help the governments in designing preventive measures of human trafficking. In addition, a focus on these factors will also "enhance the human rights component of trafficking prevention policies". (UNODC, 2008).

On Art 9, the Trafficking Protocol identifies potential vulnerability factors, such as "poverty, underdevelopment and lack of equal opportunity", which origin states are advised to address. The recognition of poverty as well as other inequality factors as a vulnerable element that pushes individuals to human trafficking and endangered migration leads the Protocol in advising origin countries to take social measures to address economic difficulties. Despite that International Legal instruments on Human trafficking are very clear in urging States to address vulnerability factors of human trafficking, none of the instruments indicates which State, origin or destination has to intervene on vulnerability factors (Kuper, 2005). According to Gallagher (2010), both origin and destination States should address vulnerable factors, in order to prevent and also respond to the victims' vulnerabilities. Considering that human trafficking tends to move people from areas with a wider social and economic gap, less wealth and opportunities to countries with bigger incomes and opportunities, broader preventive measures should be applied in origin countries in order to diminish inequality gap between citizens. ${ }^{16}$ However, rather than implementing social or economic measures in order to address deep root problems shared by victims of trafficking, origin States have been mainly focusing only on awareness campaigns against Trafficking.

15 07/01/2010 Rantsev v. Cyprus and Russia, Application no. 25965/04

16 Council of Europe Treaty Series- No. 197, 2005, European Trafficking Convention Explanatory Report, Warsaw, 16.V.2005 


\section{The gender Mainstream as recognition of vulnerability}

Besides the mentioned individual vulnerable characteristics, the International Legal Instruments also refer to main vulnerable groups sharing common features, such as gender and age. For instance, the Warsaw Convention indicates women as often marginalised individuals more exposed to poverty and unemployment than men. Moreover, according to the CEDAW Committee's General Recommendation No. 19 (1992) gender shaped factors such as poverty and unemployment increment women's vulnerability to human trafficking, especially sexual exploitation. While in prostitution, the precedent vulnerability is intensified by the marginalization of this group and the tendency to be invisible to society. Addressing gender shaped pull factors can be a long term scope that includes several steps.${ }^{17}$ According to the OSCE Action Plan the steps to diminish gender inequality are mainly based on improving education opportunities and access to credit finance, especially for women. ${ }^{18}$ Furthermore, the establishment of a minimum wage, as well as employment rights can improve women's living standards and create more economic and social opportunities. ${ }^{19}$ Developing political and social measures on this direction permits women to decrease gender vulnerability that tend to be one of the main pull factors to feminized migration and exposure to exploitation and traffickers.

The Directive 2011/36 has also adopted a gender mainstream approach by identifying sexual exploitation more gender related and proposes to the Member states to provide gender specific assistance and support measures to the victims. Furthermore, the Directive 2011 indicates that the abuse of particular vulnerabilities, usually reflected on national legislations by age and physical or psychological disabilities, should be considered an aggravated offence, which requires a more severe penalty. Vulnerability of women has been taken in particular attention by International Legal Instruments, such as the CEDAW, the Inter-American Convention on Violence against Women and the Istanbul Convention. In addition, African legal Treaties on Human Trafficking, such as the Declaration on the Fight Against Trafficking in Persons (2001) and ECOWAS Initial Plan of Action Against Trafficking in Persons (2002-2003) has targeted mainly women and children as vulnerable subjects to human trafficking.

17 UN Committee on the Elimination of All Forms of Discrimination against Women , "Concluding Observations: Viet Nam," UN Doc. CEDAW/C/VNM/CO/6, Feb. 2, 2007, at para. 19; "Concluding Observations: Nicaragua," UN Doc. CEDAW/C/NIC/CO/6, Feb. 2, 2007, at para. 22; "Concluding Observations: The Philippines," UN Doc. CEDAW/C/PHI/CO/6, Aug. 25, 2006 , at para. 20; UN Committee on the Rights of the Child, "Concluding Observations: Mauritania," UN Doc. CRC/C/MRT/CO/2, June 17, 2009, at para. 78; “Concluding Observations: Qatar," UN Doc. CRC/C/OPSC/QAT/CO/1, June 2, 2006 , at para. 38; OSCE Action Plan, at Recommendations

18 Ministerial Council Decision No. 14/04 - 2004 OSCE Action Plan for the Promotion of Gender Equality

19 UN Commission on Human Rights, "Report of the Special Rapporteur, Ms. Radhika Coomaraswamy, on Violence against Women, Its Causes and Consequences, on Trafficking in Women, Women's Migration and Violence against Women," UN Doc. E/CN.4/2000/68, Feb. 29, 2000, 
The implementation and efforts on applying Soft Law instruments regarding to the protection of particular vulnerable groups, such as women identify the lack of motivation of national Governments to empower these subgroups. Moreover, the recognition of vulnerability attributed to a collective of individuals, reflects the inadequacy of the State itself in providing equal rights to all individuals. Nevertheless, States tend to avoid in recognizing their responsibility on the phenomenon of Human Trafficking, referring that human trafficking is performed by criminal groups and not the state itself (Gallagher, 2010). However, according to Fineman (2008), the existence of vulnerable groups is nothing more than the privilege provided by the State and its institutions to a certain limited segment and the discrimination of other groups. In fact, according to Gallagher (2010) there is a strong link between vulnerability and gender discrimination. Unstable and oppressive environments for women can push them into accepting unsafe migration arrangements, by being perceived as a better opportunity. Hence, women can be more susceptible to traffickers during the recruitment's phase, rather than men. (Gallagher, 2010)

In this case, the Protocol rather than advising the states in actuate in vulnerability factors, such as poverty, underdevelopment and lack opportunity, should recommend the adaptation of legal framework in order to empower vulnerable groups. Furthermore, the Protocol should recommend states to focus factors based in politic, social, economic, psychologically or physical grounds that often lead to vulnerability. If in one hand the affirmation of vulnerable groups reflects the discrimination of a particular collective of individuals, on the other hand, the focus on specific categorized subgroups that share a common characteristic can originate a differentiation from the rest of the society that might be considered invulnerable. Thus, the attribution of vulnerability as an universal category applied to a collectivity, under a common biologic base, such as gender or race or status based (poor or immigrants) discharges the disadvantages that can transcend identity categories, particularly at the individual level (Fineman, 2008).

\section{The concept of vulnerability in the division between Smuggling and Trafficking}

Since the legal division of Smuggling of Migrants and Trafficking of Human Beings that scholars have put into debate the legal separation on these two crimes, focusing more on the overlap occurring during the mobility of individuals, rather than the clear legal limit. Furthermore, the definition of trafficking given by the Protocol has been criticized on the last years for having a limit definition, widely vague and for its narrow application (Roth, 2012; Jansson, 2013; Gallagher, 2010). Despite the recent discussion on the subject, this chapter analyses the presence of the three elements given by the protocol: Act (transfer), Means (coercion, abduction, abuse of position of vulnerability, deceit, fraud) and Purpose (Exploitation) on the phenomena of Smuggling and Human Trafficking. 
In spite, the explicit separation between THB and Smuggling of Migrants, the Legislative Guide on the Smuggling Migrants admits the overlap between the two phenomena, by assuming that criminal networks operating on human trade can use the same routes and means to transport smuggled migrants and victims of trafficking, exposing these individuals to inhuman and degrading treatment. The overlap between the two phenomena is also considered by Gallagher (2010), which affirms that "an individual can be smuggled one day and trafficked the other day", being difficult to precise chronologically and practically the clear limitation between transferring and exploitation. Furthermore, the criminalization of irregular migration underestimates the risk exposure of migrants to criminal networks and violation of human rights (Colucello\& Massey, 2015). Therefore, even if most migrants begin their path in a vulnerable situation, the journey is an added vulnerable factor that increases the migrants' risk exposure to criminal networks.

Smuggled migrants can be mixed within other particular vulnerable categories such as victims of trafficking, non-accompanied minors, pregnant women and asylum seekers, during the travel. Furthermore, smuggled migrants can also become victims of trafficking during the travel. All these categories will have the same treatment during the travel to Europe, however by the end of the migration path, only some categories will have access to asylum, even though they have passed from the same situations. Therefore, despite the affirmation of the Legislative Guide on Smuggling about the similarities as well as the overlap between both phenomena, the application of victimization and vulnerability has been applied differently on the different Protocols.

While the concept of vulnerability has assumed an important relevance, especially on the identification of victims, on the phenomenon of Human Trafficking, on smuggling of migrants vulnerability was merely considered. The reason for this different position regarding to the concept is accompanied by the perspective that if on Human Trafficking the victim is the individual that has been or was intended to be exploited, on smuggling of migrants, the aggrieved agent is the State. Furthermore, "the abuse of a position of vulnerability" is considered on Human Trafficking to be a possible "mean" used by the offender in order to achieve the victim's consent, which in this case is irrelevant, while on smuggling of migrants the consent is considered to be always voluntarily present.

The recourse of means20, which are only present on Human Trafficking are not identified in Smuggling, since the migrants are recruited "voluntarily" and the trafficker has not the purpose to exploit them. Nevertheless, regarding to the consent, according to Bhabha and Zard (2006), often migrants consent is linked to the absence of an available and adequate alternative, which is the definition of the concept of vulnerability given by the Legislative

20Means are considered to be "threat or use of force or other forms of coercion, of abduction, of fraud, of deception, of the abuse of power or of a position of vulnerability or of the giving or receiving of payments or benefits to achieve the consent of a person having control over another person, for the purpose of exploitation. 
guide on Trafficking. In the case AA (Iraq), R (on the application of) v Secretary of State for the Home Department.171 the Court of Appeal was invited to take a decision whether the migrant that has entered initially the country through smuggling but was sexually abused or coerced into having sex with her smuggler en route was potentially a victim of trafficking who was being groomed for exploitation. According to an expert witness the mean of "abuse of position of vulnerability" was taken in consideration, since the victim had no acceptable alternative rather to submit to the abuse from the smuggler.21

Despite the main differences between the two Protocols, it is evident the plead on addressing root problems such as unemployment, poverty as being one of the main push factors into smuggling and trafficking, as well as causes of individuals' vulnerability. The synonym of poverty as a vulnerable position was given by the UNODC Model Law on Human Trafficking 2009, considering a vulnerable situation as "being in a precarious situation from the standpoint of social survival'". Furthermore, the same document identifies individuals that have "entered the country illegally or without proper documentation" as also in a vulnerable situation. In fact, the Inter American Court of Human rights on 2003, on the legal status and rights of undocumented migrants Mexico has declared that vulnerability makes unauthorized migrant workers an easy target for violations of their human rights.

The suggestion that people who were smuggled illegally in the destination country are in a situation of vulnerability, not only admits the overlap between both phenomena, but also highlights that the majority of smuggled migrant are potential human trafficking victims. In fact, analyzing the constitution of Nigerian human trafficking networks for sexual exploitation, Campana (2015) has understood that despite the smuggling networks work separately from the exploiters, both organizations are well linked. However, if we look into passive vulnerability as synonym of poverty, discrimination and inequality, aren't we looking into the same features of the migrants arriving by the Mediterranean? Furthermore, should not those features be considered also when someone is exposing themselves to a criminal network, especially when considering the active vulnerability, which is created by the trafficker/recruiter/smuggler. In fact, the exposure of criminal networks is considered on the Art 15 of the Smuggling Protocol, where the States are advised to cooperate in order to prevent "potential migrants from falling victim to organized criminal groups". Moreover, Art 15 recommends also the States to prevent "irregular migration" by working on the so-called push factors, which as we compared previously can be considered vulnerable social and economic features common to human trafficking victims, such as poverty and underdevelopment. When Art 15 of the Smuggling Protocol confirms the existence of root socio-economic causes, such as poverty and underdevelopment, it is also assuming of the existence of such vulnerable groups that share a common feature, which exposes individuals to criminal networks. In this case, the sum of the active vulnerability, created

21171 [2012] EWCA Civ 23 (24 January 2012), available from: http://www.bailii.org/ew/cases/EWCA/ Civ/2012/23.html. 
by criminal groups plus the passive vulnerability of groups creates, without doubt a potential abuse of the position of vulnerability. Furthermore, the recommendation that states should address the potential vulnerable groups in the Smuggling and Trafficking Protocol, recalls Fineman's (2008) theory on Vulnerability that vulnerable groups are a product of society, in which the state has failed to defend their rights or empower.

The Directive 2011/36 perceives the "abuse of position of vulnerability", from the perpetrator side, which can aggravate the trafficker's prosecution. Despite that the Legislative Guide on smuggling agrees that exploitation might happen in smuggling of migrants, yet it is only considered as an aggravating circumstance and not as an element of Human Trafficking. It is interesting here, how the Smuggling Protocol annuls one of the most known Trafficking methods, usually also known as an indicator, in which migrants often do not pay for their travelling, putting themselves into a debt. The debt method, based on "travel first and pay it later" is used by human traders as a recruiting method in order to create a demand for migration, based exactly on the lack of economic resources of the victims, currently named on the Trafficking Protocol as "abuse of position of vulnerability".

The position of vulnerability, in this case, not only lays on the lack of economic resources, but also on the lack of education and awareness of the destination country, especially on the smugglers/traffickers expenses on the travel and the later amount that has to be returned. Additionally, the debt contraction has been developed by trafficking networks, especially by Nigerian citizens for the purposes of sexual exploitation or the exploitation of Egyptian non accompanied minors, which are categorised as vulnerable groups. However, recently during the migrant arrivals in Sicily it has been verified that migrants who are not considered within a vulnerable category, such as asylum seekers, human trafficking victims or non-accompanied minors, did not paid for that travel, in order to pay on the destination country with their future salary. This situation indicates that human smugglers have better connections with the destination countries, in order to achieve a higher profit, therefore creating more supply of migrants to transfer, which creates a discount that will be paid later by the migrants' exploitation.

Migrants' stories that have passed the Mediterranean indicate that many migrants have been taken to work in camps in Libya or abducted in order to pay for their journey. The presence of exploitation, along with the elements mentioned by the subparagraphs (b) or (c) of Art 3 from the Trafficking Protocol can make a trafficking offence applicable. However, sometimes is difficult to identify the term exploitation, which has been debated among scholars, since the Protocols do not apply an exact definition to term. For instance, a larger focus has been attributed to the issue of sexual exploitation, which was mainly left "in blank" by the Protocol, since the states have decided that sexual exploitation should be established according to national legislation. For example, while in Sweden sexual work is always considered sexual exploitation, in other countries, such as Holland sexual exploitation is legally different that sexual work. In order to overpass the national legislation on 
sexual purposes, ILO presents a clearer definition of sexual exploitation that depends on the relationship between the employer and employee and not the activities itself.

As we have verified until now, the first two elements are easily identified on the phenomenon of Smuggling, yet the Purpose is the element which is not recognized on the majority of the cases, even if the smuggling was through the debt bondage. This might happen, since on the majority of the cases, the exploitation is present by the end of the process and not during the process (Lee, 2007). However, in the phenomenon of trafficking, exploitation can be considered even if it hasn't been put into practice, remaining only an intention of the perpetrator. Therefore in the case of smuggling, why the possibility of exploitation is not recognized? Furthermore, the Protocol has provided a vague definition of Purpose, in which States are able to adequate to their National Legislation. For instance, Colombia has attributed: financial gain or other benefits to their Purpose definition. The attribution of a wider definition to the element of Purpose permits to identify trafficking situation in smuggling cases, which the other two elements have been recognized, since criminal organizations always profit from smuggled migrants.

Despite the evident overlap between human trafficking and smuggling of migrants, especially in the Mediterranean area, the two phenomena are still regarded as legally separated. However, more attention has been giving to the violation of human rights during the travel through the Mediterranean, especially after the operations Glauco I and Glauco II. According to the Palermo Prosecutor Ferrara (2015), smuggled migrants suffer more violation of human rights rather than identified human trafficking victims. Depending on the structure and power of the trafficking network, potential human trafficking victims are tendentiously saved from massive violation and abuse due to their future exploitation, whilst smuggled migrants have no further use for traffickers. Therefore, even if trafficking is not recognise in smuggled migrants, due to the absence of the three elements, shouldn't the governments be looking into the violation of human rights during the travel, rather than if the process has achieved its full goal?

\section{Conclusion}

The concept of vulnerability has emerged on the last century on the International Legal Framework in Human Trafficking as one of the "Means" to define a potential human trafficking victim. However, being considered a broad and unlimited concept, several critics have been given to the imprecise definition provided by the several Soft Law Instruments that define vulnerability as "lack of an alternative situation", but do not precise what an alternative situation can be. Furthermore, the lack of demonstration of the "Abuse of position of Vulnerability" has attributed to the mean the consideration of a "soft mean" that has demonstrated to be frequently difficult to prove in court. In fact, the "mean" of Abuse of Position of Vulnerability has been mainly considered in Court accompanied by 
other "means" such as coercion or force. However, despite the difficulty in demonstration and especially the delimitation of such concept, the "mean" of Abuse of Position of vulnerability has showed to be particularly relevant, when considered in cases of the "active vulnerability", where the recruiter is the one that creates the victim's vulnerability in order to attract the victim to human trafficking. Therefore, the abuse of Position of Vulnerability has demonstrated to be considered important in cases where the loverboy method was used, being proved with a psychological exam to the victim.

Despite the overlap between the phenomenon of Human Trafficking and Smuggling, the concept of Vulnerability has not been taken as much consideration regarding the phenomenon of Smuggling of Migrants. In fact, if in Human Trafficking the "Mean" has been considered to identify a potential human trafficking victim, while in Smuggling the application of such "mean" would only be used as an "aggravate" offence to the smuggler, since the migrants are not consider victims of such phenomenon, even when they were not aware of harsh conditions and the inhuman and degrading treatment of the smugglers. According to Médecins sans Frontiers, over $60 \%$ of the Migrants that arrive in Europe through the Mediterranean have psychological problems due to the torture suffered in the transit countries, being the travel a vulnerability factor itself. In fact, the migrants tend to arrive more vulnerable to Europe than when they have departed from their origin country. Therefore, shouldn't vulnerability among with the exposure to criminal networks be considered in the process of asylum seekers in the arrival to Europe?

\section{Bibliography}

Bhabha, Jacqueline, Zard, Monette Smuggled or Trafficked, Forced Migration Review Vol. 25, (2006) pp 6-8

Jansson, Borg, Modern slavery: A Comparative Study of the Definition Trafficking in Persons, International studies of Human Rights, 2013, Brill Nijof

Campana, Paolo, Lifting the Bonnet on a Nigerian Transnational Network, Br J Criminol (2015) Vol 56 (1): 68-86. DOI: https://doi.org/10.1093/bjc/azv027

Coluccello, Rino, Massey, Simon, Eurafrican Migration: Legal, Economic and Social Responses to Irregular Migration, 2015, Palgrave

Fineman, Martha Albertson, The Vulnerable Subject: Anchoring Equality in the $\mathrm{Hu}-$ man Condition, Yale Journal of Law \& Feminism Volume 20 Issue 1, Article 2, 2008

Kuper, A., Global Responsibilities: Who Must Deliver on Human Rights? S. Wolte, "Armed Conflict and Trafficking in Women", 2005 ed., (Deutsche Gesellschaft für Technische Zusammenarbeit (GTZ) GmbH, 2004), available at http://www2.gtz.de/dokumente/ bib/04-5304.pdf 
Rehn, E., Sirleaf, E., Women, War, Peace: The Independent Experts' Assessment on the Impact of Armed Conflict on Women and Women's Role in Peace-Building (Progress of the World's Women 2002, Vol. 1), 2002, Roth, Venla,, Defining Human Trafficking and Identifying Its Victims: A Study on the Impact and Future Challenges of International, European and Finnish Legal Responses to Prostitution-Related Trafficking in Human Beings, Int J Refugee Law first published online September 10, 2012

Wrabetz, J., Penedo, R Trafficking in Human Beings in Time and Space. A Socioecological Perspective, in Guia, Maria João, The Illegal Business of Human Trafficking, Springer, 2015

UNODC, Gallagher, A., (2015), The concept of "Exploitation" in the Trafficking in Persons Protocol,

UNODC, UNGIFT (2008), An Introduction to Human Trafficking: Vulnerability, Impact and Action.

\section{Legal Framework Documents}

Council of European Union, The Brussels Declaration on Preventing and Combating Trafficking in Human Beings, Brussels, 29th November 2002.

Council of Europe Treaty Series- No. 197, 2005, European Trafficking Convention Explanatory Report, Warsaw, 16.V.2005

ECOWAS, Ougadougou Action Plan to Combat Trafficking in Human Beings, Especially Women and Children, Adopted by the Ministerial Conference on Migration and Development, Tripoli, 22-23 November 2006.

Ministerial Council Decision No. 14/04 - 2004 OSCE Action Plan for the Promotion of Gender Equality

Economic Community of West African States, Communauté Economique des États de l'Afrique de l'Ouest, Declaration on the Fight Against Trafficking in Persons (2001)

Economic Community of West African States, Communauté Economique des États de l'Afrique de l'Ouest, ECOWAS Initial Plan of Action Against Trafficking in Persons (2002-2003), Executive Secretariat Dakar 2001

European Commission, 29 April 2004, Council Directive 2004/81/EC, European Commission, DIRECTIVE 2011/36/EU OF THE EUROPEAN PARLIAMENT AND OF THE COUNCIL of 5 April 2011 on preventing and combating trafficking in human beings and protecting its victims

European Parliament's Resolution A4-0326/95 Official Journal C 032, 05/02/1996 P. 0088

European Human Rights Court, 07/01/2010 Rantsev v. Cyprus and Russia, Application no. $25965 / 04$ 
Europol, "Trafficking in Human Beings in the European Union: A Europol Perspective," June 2009, at 3.

Explanatory Report on the Convention on Action against Trafficking in Human Beings, ETS 197, 16.V.2005 (European Trafficking Convention Explanatory Report).

International Labour Office, "Operational Indicators of Trafficking in Human Beings" Council of Europe,

La Cour Nationale du Droit D’Asile Decision n: 10012810, Audience 3 March 2015

OSCE Action Plan, at Recommendations Ministerial Council Decision No. 14/04 2004 OSCE Action Plan for the Promotion of Gender Equality

UN Committee on the Elimination of Discrimination against Women, "General Recommendation No. 19: Violence against Women," UN Doc. A/47/38, Jan. 29, 1992 (CEDAW General Recommendation No. 19),

UN Commission on Human Rights, "Report of the Special Rapporteur, Ms. Radhika Coomaraswamy, on Violence against Women, Its Causes and Consequences, on Traffi cking in Women, Women's Migration and Violence against Women," UN Doc. E/CN.4/2000/68, Feb. 29, 2000,

UN Committee on the Elimination of All Forms of Discrimination against Women, "Concluding Observations: Viet Nam," UN Doc. CEDAW/C/VNM/CO/6, Feb. 2, 2007;

UNODC, 2004, legislative guides for the implementation of the united nations convention against transnational organized crime and the protocol thereto, New York

UNODC, 2006, Travaux Préparatoires of the negotiations for the elaboration of the United Nations Convention against Organized Crime and the Protocols thereto

UNODC, 2009, 09-81990 (E) Model Law against Trafficking in Persons

United Nations, Protocol to Prevent, Suppress and Punish Trafficking in Persons Especially Women and Children, supplementing the United Nations Convention against Transnational Organized Crime, Adopted and opened for signature, ratification and accession by General Assembly resolution 55/25 of 15 November 2000

United Nations, Protocol against the Smuggling of Migrants by Land, Sea and Air, supplementing the United Nations Convention against Transnational Organized Crime, supplementing the United Nations Convention against Transnational Organized Crime, 2000

Artigo Recebido a 04 de fevereiro de 2017 | Aceite a 03 de julho de 2017 